\title{
Avaliação e pressupostos bachelardianos: tecendo relações para a formação docente em Ciências e Matemática
}

Evaluation and Bachalard's presuppositions: weaving relationships for teacher education in Science ande Mathematics

\author{
Maria Augusta Raposo de Barros Brito ${ }^{1}$ \\ Isabel Cristina Rodrigues de Lucena² \\ Eduardo Paiva da Ponte Vieira ${ }^{3}$
}

\section{Resumo}

O presente texto tem como objetivo geral apresentar contribuições dos pressupostos Bachelardianos para orientar a formação docente no campo da avaliação. A educação em um paradigma aberto demanda ao professor repensar seus métodos e suas crenças, pensar todas as possibilidades experimentais e ser capaz de pensar por meio de suas crenças e verdades em novas possibilidades para implementar um processo de ensino e aprendizagem que busque um racionalismo, tal qual problematizado por Bachelard. É preciso compreender que para avaliar devemos ultrapassar a intuição sensível, ou seja, que é preciso fortalecer o debate para que se possa cada vez mais compreender sua natureza e suas possibilidades, para a formação de um novo espírito científico, contrapondo-se às formas tradicionais de avaliar.

Palavras-Chave: Avaliação; Ensino; Formação Docente.

\section{Abstract}

This text aims to present the contributions of Bachelardian assumptions to guide teacher education in the field of evaluation. Education in an open paradigm requires teachers to rethink their methods and beliefs, to think through all experimental possibilities and to be able to think through their beliefs and truths into new possibilities to implement a teaching and learning process that seeks rationalism, such as which is problematized by Bachelard. It is necessary to understand that to evaluate we must overcome the sensitive intuition, that is, that it is necessary to strengthen the debate so that one can increasingly understand its nature and its possibilities, for the formation of a new scientific spirit, opposing to traditional ways of evaluating.

Keywords: Evaluation; Teaching; Teacher Training.

\footnotetext{
${ }^{1}$ Universidade Federal do Pará | araposo@ufpa.br

${ }^{2}$ Universidade Federal do Pará | ilucena@ufpa.br

3 Universidade Federal do Pará | epontesvieira@ufpa.br
} 


\section{Pensar a Avaliação a partir de Bachelard}

Gaston Bachelard (1884-1962) foi um dos principais pensadores da era moderna, com contribuições relevantes para a epistemologia, estendendo-se em menor escala até mesmo para a gnosiologia. Para Bachelard, a filosofia da ciência é aberta, pois seus princípios não são intocáveis e suas verdades não são totais e acabadas, não obstante, o ser humano é uma totalidade para Bachelard, a partir de sua compreensão de que razão e imaginação são caminhos fundamentais e indispensáveis para a nossa constituição (MACHADO, 2016).

Nesse contexto, o "homem"/"humano" que Bachelard concebe, chama-se "o homem das 24 horas", cuja existência não se resumiria em 12 horas, que se limitam ao diurno ou ao noturno, mas um ser que vive os dois, e capaz de problematizar e propor de forma incessante (PEREIRA; VIEIRA, 2016). Nesta perspectiva, Bachelard (2004) admite a impossibilidade das verdades absolutas e a possibilidade de apenas alcançarmos um conhecimento aproximado, deste modo, ele critica o ensino de ciências físicas no sistema escolar elementar francês do século XX, propondo que a educação se faz com a formação do espírito científico (2008).

A filosofia do inexato, tendo a razão e a imaginação como dois pilares para a construção do conhecimento, por meio de aproximações contínuas, e não por repetições de absolutas verdades instaura-se nos pressupostos bachelardianos, convidando-nos e estender tais prerrogativas aos múltiplos campos de saber e desta forma, ao exercício de pensar, criar novos objetos e tendo a possibilidade de aguçar a predominância do conhecimento abstrato e científico sobre o conhecimento primeiro e intuitivo, firmando um divisor de águas na forma de compreender o conhecimento propriamente dito (BACHELARD, 1996).

Gaston Bachelard, não trata em específico de avaliação, mas traz em sua obra a preocupação quanto à Formação do Espírito Científico ${ }^{4}$ o que contribui para se pensar a produção do conhecimento numa perspectiva histórica, que por conseguinte, poderá auxiliar professores na compreensão do conhecimento, e de modo, especial o conhecimento sobre avaliação, distante do paradigma de um pensamento universalizante. Assim, possibilitando a admissão de que os objetos do conhecimento dependem do referencial, não podendo ser absolutos, passando por um único método empírico. Nessa direção, podemos afirmar que a educação como fenômeno de investigação é fruto de um tecido de relações, consequentemente, que não está dado e é permanentemente construído.

A educação em um paradigma aberto demanda ao professor repensar seus métodos e suas crenças, pensar todas as possibilidades experimentais e ser capaz de pensar por meio de suas crenças e verdades em novas possibilidades para implementar um processo de ensino e aprendizagem que busque um racionalismo, tal qual problematizado por Bachelard. É na perspectiva da reconstrução dos eixos racionais, ou seja, é na condição do uso de um pensamento capaz de ultrapassar o espírito do estado concreto a respeito de

\footnotetext{
${ }^{4}$ A Formação do Espírito Científico, em referência ao original publicado em 1938 "La Formation de l' esprit scientifique: contribution à une psychanalyse de la connaissance" na qual Bachelard concebe a possibilidade do saber a partir da negação, apresentando a noção de obstáculo epistemológico como categoria fundamental para compreender a epistemologia, nestes termos, admitindo que a formação do espírito científico é alcançada por meio da superação dos obstáculos epistemológicos.
} 
qualquer fenômeno que o professor poderá compreender, neste caso a avaliação, como um objeto múltiplo.

A avaliação ou a didática, em termos alargados, necessitam que a escola seja o local da produção de conhecimentos e de rupturas com o que está posto. Articular imaginação e técnica pelo processo dialético e dialógico numa constante retificação em busca de um conhecimento objetivo, em especial da avaliação, se faz fundamental para se compreender, analisar e implementar práticas que ultrapassem a tradição avaliativa e que não podem estar desassociadas da sua construção histórica e epistemológica.

Bachelard, nos apresenta o raciocínio do caminho percorrido das etapas históricas do pensamento científico dividido em três momentos: estado pré-científico (Antiguidade Clássica quanto os séculos do renascimento e de novas buscas dos séculos XVI, XVII e XVIII); estado científico (estágio de preparação no fim do século XVIII até o início do século XX); e o estado do novo espírito científico (iniciado no ano de 1905 com a Teoria da Relatividade de Einstein). É no estado pré-científico que Bachelard, considera o nascimento da ciência, com uma visão mais aguçada do mundo fenomênico, envolto por metáforas, imagens, generalizações impossibilitando o processo de abstração para a formação do espírito cientifico, a esta impossibilidade chama de obstáculos epistemológicos, conceito fundamental de sua obra "A Formação do Espírito Cientifico", posicionando sua análise na relação entre a experiência e a abstração, tarefa fundamental do espírito científico, pois

[...] é no âmago do próprio ato de conhecer que aparecem, por uma espécie de imperativo funcional, lentidões e conflitos. É aí que mostraremos causas de estagnação e até de regressão, detectaremos causas de inércia às quais daremos nome de obstáculos epistemológicos (BACHELARD, 1996, p. 17).

Os atos impeditivos para a formação do espírito científico ocorrem por meio dos obstáculos, ou seja, atos que provocam a estagnação e regressão no processo de evolução da ciência e de apropriação do próprio conhecimento. Da percepção ingênua do fenômeno, o espírito pré-científico, que perdurou até o século XVIII, precisou ultrapassar os obstáculos epistemológicos para alcançar um estágio científico.

O progresso do pensamento científico se faz graças à transposição de tais obstáculos e à prática de atos epistemológicos, com efeito, aprender ciências e matemática é um movimento que pode lançar mão destes pressupostos e na mesma vertente, avaliar a aprendizagem é algo que pode (deve) ser pensado nestes termos.

\section{Formação Docente, Avaliação e Epistemologia}

Segundo Bachelard (1996, p. 17), o obstáculo não é a resistência da natureza, nem dos aspectos econômicos ou da fragilidade do pensamento humano, "O ato de conhecer dá-se contra um conhecimento anterior, destruindo conhecimentos mal estabelecidos, superando o que, no próprio espírito, é obstáculo à espiritualização". Desta forma, o desenvolvimento da ciência se dá por um processo descontínuo, onde há a necessidade de se romper com um conhecimento anterior, destruí-lo para poder assim construir um novo. Bachelard, se surpreende ao reconhecer que muitos professores não conseguem entender o porquê de um aluno não entender um conteúdo. 
os professores de ciências imaginam que o espírito começa como uma aula, que é sempre possível reconstruir uma cultura falha pela repetição da lição, que se pode fazer entender uma demonstração repetindo-a ponto a ponto. Não levam em conta que o adolescente entra na aula de física com conhecimentos empíricos já construídos; não se trata, portanto, de adquirir uma cultura experimental, mas sim de mudar de cultura experimental, de derrubar os obstáculos já sedimentados pela vida cotidiana (BACHELARD, 1996, p. 23).

O processo descontínuo presente na construção da ciência também se remodela quando da elaboração de aprendizagens nos momentos de aula e, portanto, a linearidade de uma aula apresentada pela exposição seguida de exemplos e exercícios comuns "às práticas dos professores, uma vez que estes não parecem fazer uma contextualização das situações de aprendizagem, sendo que o que prevalece na sala de aula são as exposições do professor e a resolução sistemática de exercício" (FERNANDES, 2007, p.27) configura-se como um obstáculo para a melhoria das aprendizagens escolares, principalmente no campo das ciências e matemática.

É importante ressaltar que essa prática não é exclusividade do professor de ciências ou de matemática, assim, se avaliar ocorre aquisição ou mudança nos termos propostos por Bachelard não seria algo possível sem a problematização do processo avaliativo. Os professores, em sua formação acadêmica e mesmo tendo acesso a respeito do tema avaliação, mantém uma centralidade em relação à compreensão da mesma enquanto fenômeno, nestes termos, uma "avaliação" dogmática repousa nas imagens primeiras, que podem ser os artefatos e o simbolismo experenciado pelos próprios docentes em sua vida estudantil e que acabam fundamentando sua concepção inicial sobre o que vem a ser avaliar.

Há uma concepção bucólica sobre o tema na qual temos uma tradição avaliativa e que reforça práticas consagradas historicamente não colocando estas mesmas práticas em estado de suspensão, em uma epistemologia crítica. Neste estado predomina um conhecimento comum e vulgar do realismo ingênuo.

A avaliação das aprendizagens em ambiente escolar tem seguido um fluxo de práticas sedimentadas como próprias, vistas como "naturais" deste lugar. Tempos, gestão e instrumentos para a avaliação de aprendizagens têm-se repetido por décadas salvo algumas problematizações. Em geral as sedimentações são caracterizadas por: a) uma avaliação onde o professor assume com exclusividade o papel de avaliador e, portanto, o responsável pela seleção de critérios de averiguação e de intervenções para melhoria dos resultados no contexto da sala de aula; b) instrumentos de avaliação para verificação de resultados ao final de um determinado período, geralmente individuais e no formato de testes ou provas com sentido de "medir" em alguma escala pré-definida para este fim qual a "nota" alcançada pelo estudante; c) uma avaliação não integrada aos processos de ensino-aprendizagem, que ocorre de forma estanque em períodos próprios e comuns a toda a escola.

Ao considerar que a postura do professor em sala de aula é determinante para possibilitar que o aluno desenvolva recursos cognitivos para aprender torna-se essencial que o ensino esteja para melhorar as aprendizagens, e que a avaliação esteja integrada a este processo. 
Assim o processo seria de ensino-aprendizagem-avaliação e as possibilidades de descobertas para o aluno, promovidas pelo professor, teriam que se assumir em uma variedade de tarefas também instrumentos no contexto da avaliação. Tarefas selecionadas pelo professor, discutidas com os estudantes, utilizadas para o ensino-aprendizagemavaliação no cotidiano da sala de aula. Menino e Santos asseveram que:

O uso variado de instrumentos de forma integrada no ensino permite, por um lado, a existência de uma avaliação consistente com o ensino e aprendizagem, contribuindo para o desenvolvimento de sua função reguladora; e, por outro lado, permite reunir um conjunto significativo de evidências daquilo que $\mathrm{O}$ aluno melhor consegue fazer em diferentes tarefas e em diferentes contextos de trabalho. (MENINO; SANTOS, 2004, p.2).

A diversidade, escolha e a utilização do instrumento não podem ter um fim em si mesmos, pois "a avaliação não se reduz à aplicação de uns tantos instrumentos" (BORRALHO et al., 2015, p.34). Cada instrumento de avaliação com suas características, vantagens e desvantagens são eleitos de acordo com a concepção e objetos que o professor adota e pode permitir mais possibilidades de aprendizagem e acompanhamento das aprendizagens tanto pelo professor quanto pelos próprios estudantes. Assim,

Em se tratando de uma avaliação para as aprendizagens formativa, os aspectos com fins formativos que mais interessam são: a natureza e diversificação das tarefas de ensino-aprendizagem; a qualidade e quantidade do feedback prestado aos estudantes; a clareza e partilha de critérios entre os alunos; bem como o uso constante de auto e heteroavaliação. (LUCENA; BORRALHO; DIAS, 2018, p.259).

É preciso romper com o paradigma e a pragmática da avaliação sedimentada nas práticas do senso comum, onde esta avaliação é tida com propósito mais classificatório que formativo. Adentrar o espectro de significados e condições com compreensão e ações de uma avaliação para as aprendizagens, e não somente de aprendizagens, é um caminho a percorrer visando a superação de obstáculos na formação do espírito científico nos contextos áulicos de ciências e matemática e, também, nos contextos de práticas da avaliação que o professor seleciona e executa, pois, durante o processo de aprendizagem o professor necessita excluir obstáculos epistemológicos de sua prática docente e atentar para a possibilidade de utilização de outras estratégias de avaliação que cada vez mais contribua para melhorar as aprendizagens dos estudantes.

\section{Avaliação escolar e interfaces bachelardianas: fenômeno em contextura}

Gaston Bachelard, mesmo não abordando exclusivamente assuntos sobre a prática avaliativa, realizou uma abordagem sobre o conhecimento científico referindo-se, entre outros aspectos, ao ensino de química no espaço escolar, tendo em vista a proposta de um novo espírito científico que desvela os fundamentos e os requisitos essenciais para a 
compreensão de um conhecimento científico, que possa alicerçar um novo pensar, e no caso deste ensaio, para o ato de avaliar, de modo que:

Ninguém pode arrogar-se o espírito científico enquanto não estiver seguro, em qualquer momento da vida do pensamento, de reconstruir todo o próprio saber. Só os eixos racionais permitem essa reconstrução. $O$ resto é baixa mnemotecnia. A paciência da erudição nada tem a ver com a paciência científica (BACHELARD, 1996, p.10).

Assim, assume-se que eixos racionais são dispositivos de pensamento sobre o conhecimento, em especial da avaliação, numa perspectiva de uma pedagogia científica que busque romper com um pragmatismo ingênuo. De outro modo, é dizer de uma forma de pensar sobre a avaliação, e sobre este pensar, racionalizar de tal maneira que a tome como um sistema de pensamento. A concepção de Bachelard percorre na possibilidade do rompimento com o conhecimento superficial para ir em busca de posicionamento científico para a construção do conhecimento científico. Ao nosso ver é nesta linha, a de romper como o conhecimento superficial, que o debate e a prática da avaliação devem ancorar-se.

Estar permanentemente vigilante em relação aos feitos dos processos avaliativos no contexto escolar, remete ao questionamento dos modos como se pensar e se fazer essas mesmas práticas, o que pode favorecer uma avaliação ancorada na racionalidade aberta, critica e reflexiva para romper com o conhecimento usual. Ou seja, a partir de Bachelard pode-se dizer que a avaliação deve ser tomada e assumida em pressupostos da ciência e não de opinião, pois epistemologia e pedagogia devem integrar-se de modo que se tome a avaliação como um fenômeno construído. Isto é possível na medida em que o professor rompe com o conformismo intelectual, com a ideia de um saber definitivo, e passa a buscar um conhecimento aproximado, ou seja, de verdades aproximadas. Nesse sentido, Bachelard (1996, p.14), afirma que:

[...] toda cultura científica deve começar [...] por uma catarse intelectual e afetiva. Resta, então, a tarefa mais difícil: colocar a cultura científica em estado de mobilização permanente, substituir o saber fechado e estático por um conhecimento aberto e dinâmico, dialetizar todas as variáveis experimentais, oferecer enfim à razão razões para evoluir.

Diante desta assertiva, faz-se necessário que o professor estabeleça o conhecimento sobre avaliação em um estado de constante mobilização, de questionamento no sentido de buscar razões para progredir, ou seja, de verificar se há a presença de obstáculos, e se houver, problematizar sua sedimentação para assim verificar onde e em que avançar, pois, "é no momento em que um conceito muda de sentido que ele tem mais sentido" (BACHELARD, 2001, p. 116). Em termos bachelardianos, o professor deve trazer perguntas para o contexto da aula, pois a atividade acadêmica intelectual deve prescindir de um ambiente de dúvidas e inquietação.

O professor necessita realizar constantemente a problematização epistemológica sobre a compreensão do que é avaliar, não se deve furtar-se de discutir o que é fundamental ensinar na escola, bem como de não nos furtar a discutir como regulamos aquilo que ensinamos, pois:

Os professores substituem as descobertas por aulas. Contra essa indolência intelectual que nos retira aos poucos o senso da novidade espiritual, o ensino das descobertas ao longo da história científica pode 
ser de grande ajuda. Para ensinar o aluno a inventar, é bom mostrar-Ihe que ele pode descobrir. (BACHELARD, 1996, p.303).

Vendo por esta ótica, cabe ao professor desenvolver práticas avaliativas para aprendizagens que estejam coerentes com o contexto do aluno e de que forma esse aluno vai construir seu conhecimento. Entretanto, essa prática avaliativa implica em pensar a descontinuidade de um sistema de pensamento que negue as rupturas epistemológicas da construção do conhecimento, ou seja, é preciso que o professor compreenda que a avaliação para além das experiências primeiras e perceba que a produção do conhecimento deve ser assumida como uma reflexão que afeta os pressupostos da racionalidade cientifica e da racionalidade pedagógica. É nesta esteira que este estudo busca problematizar o tema avaliação, pois para melhor entendimento considero que as práticas de avaliação aceitas e movimentadas no interior das escolas precisam ser problematizadas à luz da ideia de que o ato de ensinar não se distancia da crença do saber que o professor julga conhecer, este mesmo ato. De modo similar, assumo que isto se estende à avaliação, e assim é possível dizer que não se separa a forma de pensar do professor da forma de uma epistemologia que constituiu este pensar.

Por isso, debater como se organiza ou se fundamenta, ou em quais eixos racionais o conhecimento do professor sobre a avaliação se movimenta constitui um desafio na área educacional, pois favorece a necessidade do professor desenvolver uma postura de vigilância epistemológica contínua para realizar o processo de ruptura e retificação dos erros proposto por Bachelard, para combater os obstáculos epistemológicos nas práticas avaliativas em matemática nos anos iniciais.

Para além do estatuto que dispõe os elementos que formatam ou modelizam uma prática de avaliação para as aprendizagens, afirmo também ser necessário realizar um debate no campo epistemológico, no campo da racionalidade docente como forma de analisar os contornos que os processos racionais instituídos conferem aos modelos avaliativos e assim questionar a racionalidade vigente, pois discutir no campo da racionalidade docente requer o distanciamento da atividade de docência no cotidiano mergulhado no conhecimento comum, pois "o pensamento, quando formulado em sistema, implica uma imagem, ou melhor, uma concepção do mundo, e se situa em relação a ela." (KOYRÉ, 2011, p. 1), é necessário erguer-se de outras bases, partindo de relações ainda não estabelecidas indo ao encontro de um espírito aberto deixando fluir suas particularidades e sua complexidade.

Em Cruz (2005, p.25), a pedagogia de Bachelard nos ensina a necessidade de inventarmos, e nesse sentido, destruímos teorias, métodos e metodologias, para criamos outras, mas a natureza da argumentação precisaria assumir a precisão de uma construção racionalmente constituída, uma vez que Bachelard propõe introduzir entre os dois polos do mundo destruído e do mundo construído, o retificado. E em Melo (2005), podemos compreender que a história da óptica estudada na perspectiva da epistemologia de Bachelard pode permitir o desenvolvimento do pensamento crítico-reflexivo do futuro educador acerca da imagem da ciência e do cientista disseminada no ensino de ciências.

Kaercker (2005) constata a dificuldade de se renovar as práticas pedagógicas, bem como de se construir um bom embasamento teórico que promova um ensino de Geografia atual, dinâmico, plural, instigante, reflexivo e radicalmente democrático.

Retificar o conhecimento, em especial sobre o da avaliação, é necessário de modo a possibilitar ao professor perceber-se como sujeito que compreenda que a mudança na 
concepção de avaliação implica na própria retificação da pedagogia avaliativa. Problematizar os eixos racionais sobre a prática avaliativa é buscar o que Bachelard (1996, p.308) nos orienta no sentido de compreendermos que

[...] O espírito científico proíbe-nos de ter uma opinião sobre questões que não compreendemos, sobre questões que não sabemos formular claramente. É preciso, antes de tudo saber formular problemas.

Reformar o espírito científico no âmbito da avaliação da aprendizagem refere-se buscar uma pedagogia que instrua a prática e a cultura escolar de avaliação, e com isso quero afirmar que prática avaliativa e sua arqueologia só terão novos rumos se o professor tomar o tema em foco na perspectiva epistemológica como forma de tornar a prática pedagógica cada vez mais fundamentada. Isto romperá com determinadas tradições arraigadas no interior da escola. Há que se considerar que somente pela autonomia intelectual o professor poderá ultrapassar visões simplistas acerca da avaliação.

Para Bachelard (2001), toda cultura científica deve começar por uma catarse intelectual e afetiva e pela compreensão de uma "consciência em mutação" e "por um ensino não dogmático", no sentido de promover autonomia do professor e do aluno. Como debater sobre determinada racionalidade imposta a cultura da avaliação se não se reflete sobre as formas de produção do conhecimento desta mesma cultura? Como se compreender professor, e por conseguinte avaliador das aprendizagens, se não se problematiza até que ponto o meu ensino está relacionado as minhas crenças com o meu saber? Há separação das formas de pensar sobre a avaliação e os conhecimentos que os constituem?

Ao nosso ver precisamos debater as "imagens de verdades" acerca da avaliação e assim problematizar as velhas categorias que a nomeiam, pois trilhar novos caminhos pode ser o fluxo imprescindível para a construção de uma racionalidade que libere o espírito das amarras das ideias iniciais. É preciso compreender que para avaliar devemos ultrapassar a intuição sensível, ou seja, que é preciso fortalecer o debate para que se possa cada vez mais compreender sua natureza e suas possibilidades.

\section{Referências}

BACHELARD, Gaston. A formação do espírito científico: contribuição para uma psicanálise do conhecimento. Rio de Janeiro: Contraponto, 1996. 314 p.

BACHELARD, Gaston. O novo espírito científico. São Paulo: Abril Cultural, 1978. Coleção Os Pensadores.

BACHELARD, Gaston. Ensaio sobre conhecimento aproximado. Contraponto, 2004.

BACHELARD, Gaston. O novo espírito científico. Rio de Janeiro: Tempo Brasileiro, 2001.

BORRALHO, A., LUCENA, I., BRITO, M.A. Avaliar para melhorar as aprendizagens matemáticas. Coleção IV. v 7. Educação Matemática, 2015.

CRUZ, Juliana Ferraz da. Gaston Bachelard e a formação do sujeito. Dissertação de Mestrado (2005). Goiânia - GO. Universidade Federal de Goiás. Faculdade de Educação. 
FERNANDES, C. A matemática na disciplina Físico-Químicas um estudo sobre as atitudes de alunos do $1^{\circ}$ ano de escolaridade. Dissertação de mestrado em Educação. Braga: Universidade de Minho.2007.

KAERCKER, Nestor. A Geografia escola na prática docente: a utopia e os obstáculos epistemológicos da Geografia Crítica. Tese (Doutorado em Geografia Humana) - Faculdade de Filosofia, Letras e Humanas, Universidade Federal de São Paulo, 2004.

KOYRÉ, Alexandre. Estudos de História do pensamento científico. Trad. Márcio Ramalho, 3. ed. Rio de Janeiro: Forense, 2011.

LUCENA, I; DIAS, J.; BORRALHO, A. Práticas letivas de sala de aula de matemática nos anos iniciais. Estudos em Avaliação Educacional. Fundação Carlos Chagas. São Paulo, V. 29.2018.

MACHADO, F. Diurno e noturno no pensamento de Gaston Bachelard. Cadernos do PET Filosofia, Vol.7, n.13, Jan -Jun,2016. P.11- 23 ISSN 2178-5880

MELO, Ana Carolina Staub de. Contribuições da epistemologia histórica de Bachelard no estudo da evolução dos conceitos da óptica. Dissertação (Mestrado em Educação Científica e Tecnológica) - Centro de Ciências Físicas e Matemáticas, Universidade Federal de Santa Catarina, 2005.

MENINO, H.; SANTOS, L. Instrumentos de avaliação das aprendizagens em Matemática: O uso do relatório escrito, do teste em duas fases e do portefólio no $2^{\circ}$ ciclo do Ensino Básico. 2004.

PEREIRA, J. R; VIEIRA, E. P. P. Pensando a educação através da perspectiva filosófica do diurno e noturno de Gaston Bachelard. In: VIII FIPED, 2016, Imperatriz Maranhão. Anais do VIII Fórum Internacional de Pedagogia, 2016. 